\title{
CFD STUDY ON THE ABILITY OF A VENTILATED BLADE IN IMPROVING THE SAVONIUS ROTOR PERFORMANCE
}

\author{
Rudi Hariyanto ${ }^{1 *}$, Sudjito Soeparman'2, Denny Widhiyanuriyawan ${ }^{2}$, Mega Nur Sasongko $^{2}$ \\ ${ }^{1}$ Department of Mechanical Engineering, Merdeka University, Malang - Indonesia \\ ${ }^{2}$ Department of Mechanical Engineering, Brawijaya University, Malang - Indonesia
}

This study aims to overview the ability of ventilated blades to improve the performance of the Savonius rotor based on CFD simulation. Rotor performance is analyzed by static torque, pressure profile, a airflow profile and vortex area. The boundary conditions for all simulations use the assumption that the wind speed is $5 \mathrm{~m} / \mathrm{s}$ and the environmental pressure is $1 \mathrm{~atm}$ or $101325 \mathrm{~Pa}$. The CFD simulation results have strengthen the published experimental results. Ventilation with the $5 \%$ gap width of blade diameter (the SV05 model) gives the best performance. Static torque of SV05 model is $23.8 \%$ higher than the conventional Savonius (SC) rotor. Based on pressure and airflow profile of CFD simulation results, ventilation on the blade can add the mass flow rate of air and make the lift force work early on rotating angle of $0 \mathrm{o}$ and $165^{\circ}$. Ventilation on the blade also able to improve the critical condition and vortex area as seen in the SC rotor. This is shown by a static torque from the CFD simulation results. The static torque value of the SV05 rotor are $69 \%$ and $73 \%$ higher than the SC rotor at the $165^{\circ}$ and $0^{\circ}$ rotation angle.

Key words: Ventilated blades, Savonius rotor, CFD Simulation, Vortex

\section{INTRODUCTION}

Rotor Savonius with ventilated blades or the ventilated Savonius (SV) rotor is a new innovation found by Rudi Hariyanto in 2016. Experimentally, the SV rotor was able to improve the efficiency of the SC rotor by $32 \%$ [1]. Ventilated blades do not change the basic shape of the rotor Savonius. The design of the Savonius windmill still has a very simple rotor construction so the manufacture and maintenance is easy. The blades can even be made from a split drum. The Savonius windmill is particularly suitable in areas with low wind speeds and is suitable for areas with fluctuating wind speeds [2].

Many researchers have attempted to improve the efficiency of Savonius windmill. There are researchers who focus on obtaining the optimum geometry of Savonius rotor. Variations in the number of blades, aspect ratio, end plates and overlap [3-5]. There is research that focuses on the modification of blade form, Kamoji [6] has been researching fishing rod or hook blades. Savonius rotor with hook-shaped blade is able to increase $\mathrm{Cp}$ from conventional rotor savonus by $3 \%$. Saha and Rajkumar [7] examined the use of twisted blades on a Savonius rotor. The twisted blades can improve the efficiency $2.62 \%$ higher than the SC rotor that have semicircular blades.

In addition to experimental research, numerical simulation programs are also increasingly used in the Savonius rotor research. Numerical simulation programs are able to predict fluid flow profiles. So that numerical simulation programs can be used to predict the types of losses that occur in airflow during rotating of the blades. Thus a numerical simulation program can help researchers in designing research to reduce the loss of the fluid flow.

As an example of a numerical simulation program is
Computational Fluids Dynamic (CFD) simulation. CFDs program is widely used to strengthen the analysis of the experimental research. Nakajima [8]. Gupta et al. [9], Yaakob et al. [10] and Sukanta R. [11] utilize the CFD program to find out how the width gap between the blades or overlap on the efficiency of Savonius turbine. JL Menet \& N. Bourabaa [12] and Thong, Z. \& Dietmar R., [13] use a CFD program to simulate windmill characteristics based on the fluid flow profile and wind pressure distribution passing through conventional Savonius blades.

Alesandro et al. [14] and several other researchers present graphs from rotating angles vs Ct results from the CFD simulations. The shape of the graph is similar to the Kamoji's graph [9] although the research variables studied differ. Savonius rotor has the smallest torque on the rotation angle on $150^{\circ}-165^{\circ}$. Rudi Hariyanto et al. [15] used CFD simulation to determine the effect of vortex on the Savonius's rotor performance. The results showed that the vortex is inversely proportional to Savonius's rotor torque.. The lowest torque is generated when the vortex has the largest diameter on the rotation angle of $165^{\circ}$.

This paper aims to study the ability of ventilated blades especially the SV05 model in improving the performance of Savonius rotor based on CFD simulation. CFD simulation results are expected to be able to show if the making of fixed ventilation on Savonius blades will add the mass flow rate of air that worked on the concave surfaces of the blades. The ventilation on Savonius blades will make the lift force work early on the blade and improve a critical position on the SC rotor. For futher, this paper will present a comparison between changes in airflow profile, torque and pressure distribution on SC rotor and SV05 rotor. The change in the airflow profile that rotates 
the blade will explain why the ventilated blades of the SV05 model can improve the efficiency of the SC rotor by $32 \%$.

\section{TURBULENCE MODELING}

Basically, the flow field around a blade of rotor model is highly turbulent like a result of research from Rudi Hariyanto et al. [15]. Thus, the main features of turbulence must be considered while choosing the computational technique to solve of a turbulent flow over the rotor model. Therefore, the selection of the turbulence model plays an important role for obtaining the desired computational results. Fluent simulation program for Savonius rotor can use the $\mathrm{k}-\varepsilon$ turbulence models standard. $\mathrm{K}-\varepsilon$ turbulence model of the standard has been able to provide an accurate simulation results. The use of standard $k$ turbulence model has been observed in the investigations of Pope et al. [16].

The transport equation for $(\mathrm{k}-\varepsilon)$ Standard Model are as follows:

$$
\frac{\partial}{\partial t}(\rho k)+\frac{\partial}{\partial x_{i}}\left(\rho k u_{i}\right)=\frac{\partial}{\partial x_{i}}\left[\left(\mu+\frac{\mu_{t}}{\sigma_{k}}\right) \frac{\partial k}{\partial x_{i}}\right]+G_{k}+G_{b}-\rho \varepsilon-Y_{M}+S_{k}
$$

\section{And}

$\frac{\partial}{\partial t}(\rho \varepsilon)+\frac{\partial}{\partial x_{i}}\left(\rho \varepsilon u_{i}\right)=\frac{\partial}{\partial x_{i}}\left[\left(\mu+\frac{\mu_{t}}{\sigma_{\varepsilon}}\right) \frac{\partial \varepsilon}{\partial x_{i}}\right]+C_{1 \varepsilon} \frac{\varepsilon}{k}\left(G_{b}+C_{3 \varepsilon} G_{b}\right)-C_{2 \varepsilon} \rho \frac{\varepsilon^{2}}{k}+S_{\varepsilon}$

Where,

$G_{b}$ is the generation of turbulence kinetic energy due to buoyancy;

$Y_{M}$ is the contribution of the fluctuating dilatation in compressible turbulence with the overall dissipation rate, calculated as described in Effects of Compressibility on in the k- $\varepsilon$ Turbulence Models;

$C_{1 \varepsilon}, C_{2 \varepsilon}$ and $C_{3 \varepsilon}$ is constant each worth $1.44,1.92$, and 0.09 .

$\sigma_{k}$ and $\sigma_{\varepsilon}$ turbulent Prandtl numbers for $k$ and $\varepsilon$ each worth 1 and 1.3.

\section{RESEARCH METHODOLOGY}

The modeling of ventilated Savonius rotor is carried out with the help of Mastercam modeling software. Figure 1 illustrates the sectional geometry of simulated model of the ventilated Savonius rotor. The geometry of a simulated model is made according to the size of themodel tested experimentally [rudi]. The simulatedmodel has the diameter of the blades or a semi-circle $(d)=D / 2$, the blade thickness $=0.0015^{\star} \mathrm{D}$, the width of overlap (e) $=\mathrm{D} / 10 \mathrm{~mm}$, the long side of the ventilation further pushed towards the blade (s) $=0,02$ to 0,2 ). $d$ and the width of ventilation $(a)=0,075^{*} \mathrm{D}$. The computational domain of the rectangle $\left(L^{*} L\right)$ is taken as $0.5 \mathrm{~m} \times 0.5 \mathrm{~m}$. The axis of symmetry of the ventilation long side placed right at $15^{\circ}$ from the outer end of the blade Savonius.

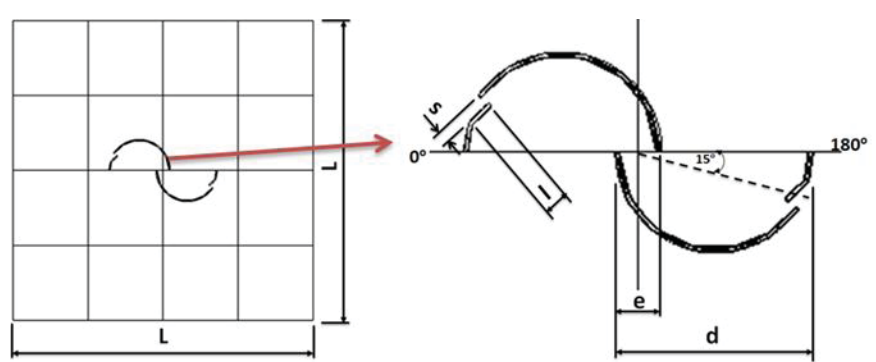

Figure 1: Cross-section 2D models of the ventilated Savonius rotor

Experimental study from a fluid flow profile and pressure distribution on the blade of Savonius rotor would require sophisticated equipment and are too expensive if done privately. Using simulation software can help to do a manipulation becomes easier and cheaper. In this study, two simulation models will be compared. Two models are one model of a ventilated Savonius rotor and the conventional Savonius rotor model. The selected model of the ventilated Savonius rotor is the SV05 model which has the best performance of the experimental test results [1].

There are two methods for present the data analisys in this study. The first method is to manipulate fluid flow profile and pressure distribution with the help of CFD code Fluent 13.0. Fluent simulation programs have the option to provide some various models of turbulence $k-\varepsilon$ containing formulations of transport for turbulence kinetic energy (k) and the rate of energy dissipation (e). The complete two-dimensional computational model includes an inner of rectangle containing the rotor model. The next step in the simulation effort is the generation of the computational mesh. Sizing of mesh use advanced size funtion on: curvature and proximate. Thus, two fluid mesh sections are clearly noticeable.

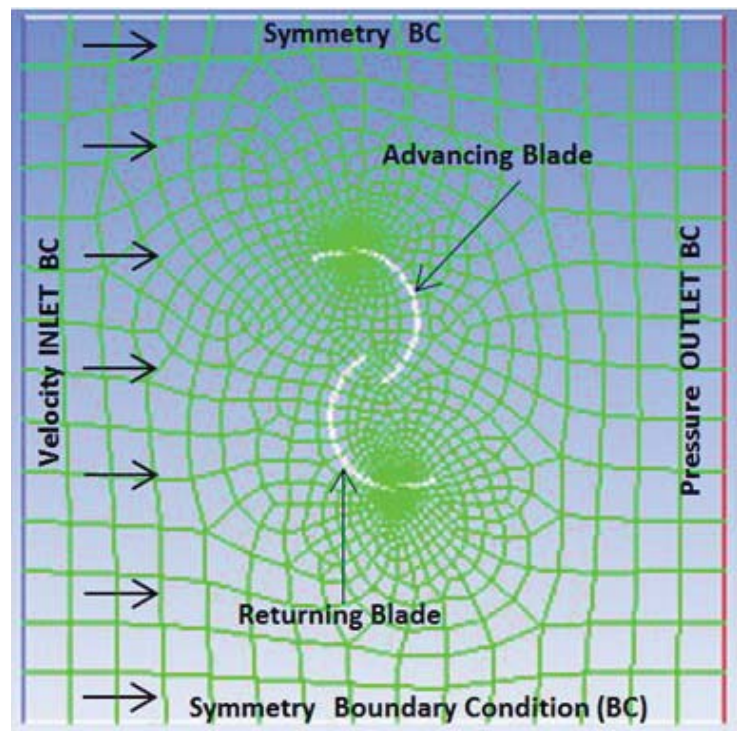

Figure 2: Grid generation around blade of the rotor model 
Figure 2 show if the grid node density utilized in the blade domain was higher than in the other domains. Mesh near the surface of the blade look smaller in size than that around the rotor. This shows the speed gradient that occurs on the surface of the blade has a very sharp angle.

Set - up boundary conditions used in CFD simulation is the inlet $v=5 \mathrm{~m} / \mathrm{s}$ (constant), outlet: pressure outlet $=101325 \mathrm{~Pa}$ (constant). The boundary conditions that used for all simulations are same as the simulation study of Rudi Hariyanto et al. [15] and the experimental study of Rudi Hariyanto et al. [1]. Solution method includes the scheme: semi - (simple), the momentum: order upwind second. In the fluid flow analysis, the convergence criterion use to solve the Navier-Stokes equation by iteration. Then the selected report of result is the static torque value.

The second method is to measure the vortex area using the Image-J program. In order to get credible and reliable data then set scale for the length of the line on each image of the simulation results. Figure 3 shows the blade diameter of $10 \mathrm{~cm}$ which is the reference standard of the line length used to obtain the vortex area.

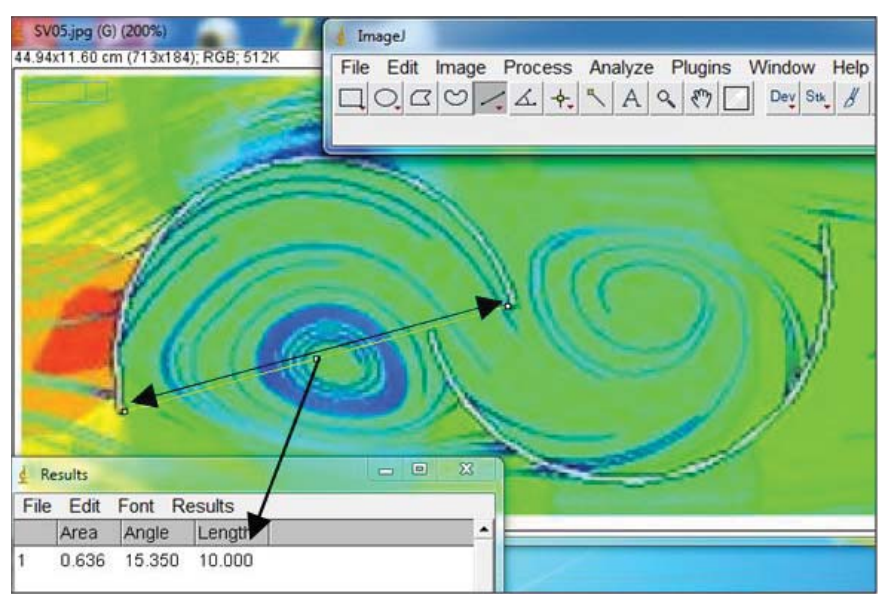

Figure 3: Set the length scale of the line with the Image-J program

\section{RESULTS AND DISCUSSION}

\section{Effect of The Ventilation on Blade to a Static Torque}

Figure 4 shows if the ventilation on the blade of the Savonius rotor able to improve a statis torque especially at $165^{\circ}$ and $0 \circ\left(180^{\circ}\right)$ rotation angles. The $165^{\circ}$ and $0^{\circ}$ $\left(180^{\circ}\right)$ rotation angles are the critical condition of the SC rotor. At the 1650 rotation angle, the ventilated blades able to improve the SC torque between $169 \%-197 \%$ and at $0^{\circ}\left(180^{\circ}\right)$ rotation angle between $157 \%-189 \%$. On both angles, the wider the gap of the ventilation increases the greater torque. This show if Ventilation of SV models are able to make the lifting force that has been working at $165^{\circ}$ rotation angle. Ventilation is able to advance the lifting force of the wind so that the wind is able to rotate the rotor before and during the rotation angle $0^{\circ}$ better. It proves if the ventilation on the blade of the rotor models capable to improve a critical condition in the conventional Savonius.

From simulated result, the static torque average of all ventilated rotor is $1,4 \%-23,8 \%$ higher than conventional Savonius. As for the SV20 model looks to have the static torque lower than the conventional Savonius for a $15^{\circ}-150^{\circ}$ rotation angle. But the static torque average of SV20 is $101.4 \%$ higher than conventional Savonius. Torque improvement by model SV20 at $165^{\circ}$ and $0^{\circ}\left(180^{\circ}\right)$ angle rotation angles are capable of covering a torque drop at $15^{\circ}-150^{\circ}$. The simulation result is identical to $\mathrm{Cp}$ from the published experimental result.

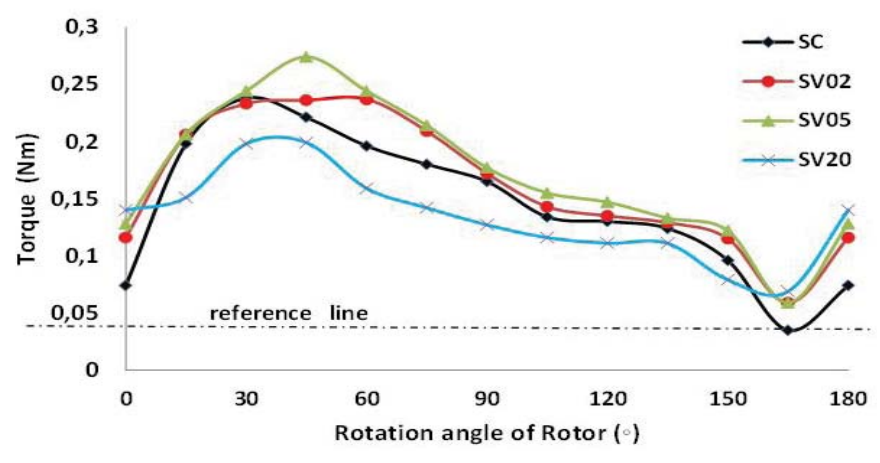

Figure 4: Effect of ventilation gap of the Savonius blades on the static torque

Ventilation on the blade is also capable of shifting the peak torque of the conventional Savonius from rotation angle of $30^{\circ}$ to $45^{\circ}$. At the rotation angle of $45^{\circ}$, the torque value of the conventional Savonius decreased by $7 \%$. The highest torque at $45^{\circ}$ rotation angle generated SV05 model with value $24 \%$ higher than torque from conventional Savonius. The SV05 model is also capable of generating static torque larger than the SC model at every rotation angle. The CFD simulation result proved to strengthen the experimental results. Thus, the ventilation on the SV05 blades can improve the efficiency of the Savonius rotor.

Pressure analysis on the concave surface of the Savonius blade

The concave side of the blade is the most important part of Savonius rotor for producing a positive force to rotate the rotor. The positive force is not only produced on the concave surface of the advancing blade $(A B)$ but also on the concave surface of the blade (RB). Figure 5 show if the ventilation on the blades of the SV05 model is capable of providing increased wind pressure on the concave surface of advancing blade by $8 \%-37 \%$ than the SC model at rotation angle of $135^{\circ}-45^{\circ}$. In a critical position at $165^{\circ}$ and $0^{\circ}$, the SV05 is able to produce wind pressure $28 \%$ and $8 \%$ greater than the SC blade. 


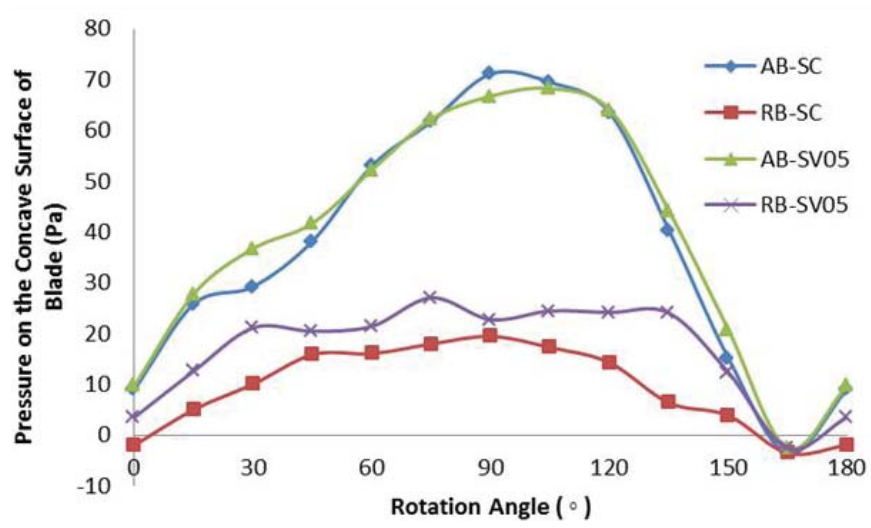

Figure 5: The pressure values on the concave surface of the blade of SC and SV

At rotation angle of $60^{\circ}-120^{\circ}$, the pressure value on the concave surface of AB SV05 is lower $0 \%-6 \%$ than the SC model. This is due to the difference between the air pressure in front of the concave surface of the blade and around the rotor. The pressure on the AB's concave surface is greater than around the rotor. So in part of the air will flow out through the ventilation gap. Thus the wind energy used to drive the concave surface becomes smaller. The greatest flow losses occur at rotation angle of $90^{\circ}$. However, the average pressure produced by the Advance Blade concave surfaces of the SV 05 model is $17 \%$ larger than the SC model when the rotor rotates 180 degrees.
The interesting data result is the increase of pressure on the concave surface of the RB-SV05. The increase in pressure is $15 \%-281 \%$. The increase in mean pressure on the concave surfaces of the RB-SV05 model is $108 \%$ when the rotor rotates 180 degrees.

Figure 6 show if concave surface of the SV05 returning blades (no. 1) has pressure value greater than the conventional Savonius. Ventilation on the SV05 blades can increase the wind pressure on both concave surface of the blades. This will certainly increase the positive force that works to rotate the rotor. If the wind velocity that passing through the blade surface is considered equal for of SC and SV05 models, then the mass flow rate at the SV05 blade surfaces are greater than the SC model. This means that the ventilation on the SV05 blade effectively adds to the mass air flow rate that drives the blade at rotation angle of $135^{\circ}-45^{\circ}$.

In addition, the wind is also pressing on the convex surface of the blade and will produce a negative force. Based on the color indicates if the pressure in front of the convex side (No. 2) of the SV05 is lower than SC blade. Thus, the negative force on the SV05 blade (no 2) was smaller than the SC blade. This causes the SV05 rotors to rotate more easily than the $\mathrm{SC}$ rotor.

Streamline analysis on the concave surface of the Savonius blade

Ventilations on the blade connect two regions that have a different of air pressures. At the rotation angle of $165^{\circ}$, the concave area of the blade has a lower pressure than the outside of the blade.
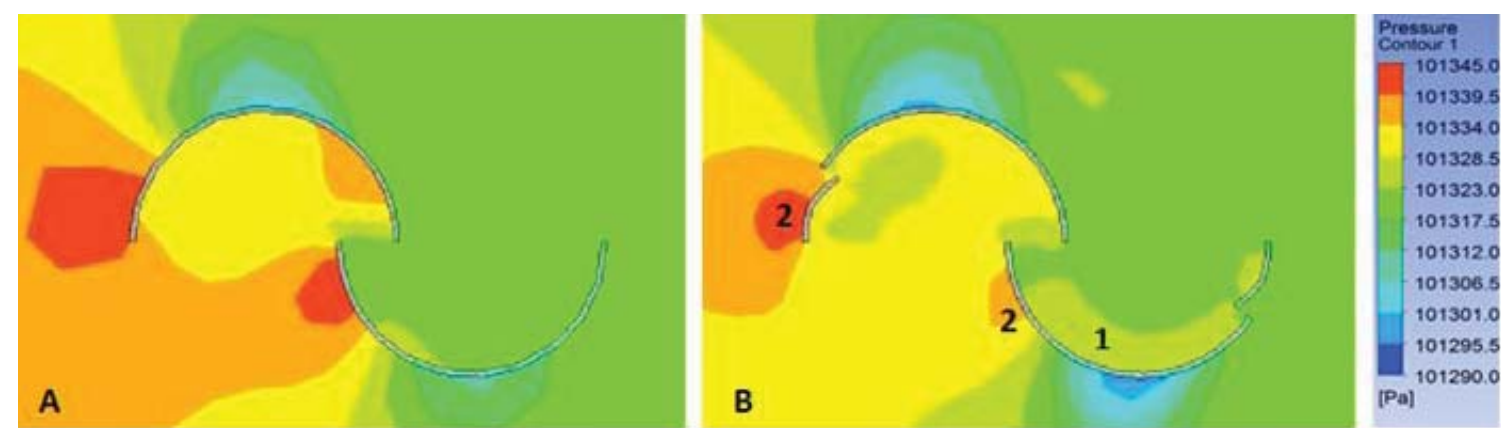

Figure 6: Pressure distribution on the rotation angle of $0^{\circ}$ (A. SC model and B. SV05 model)
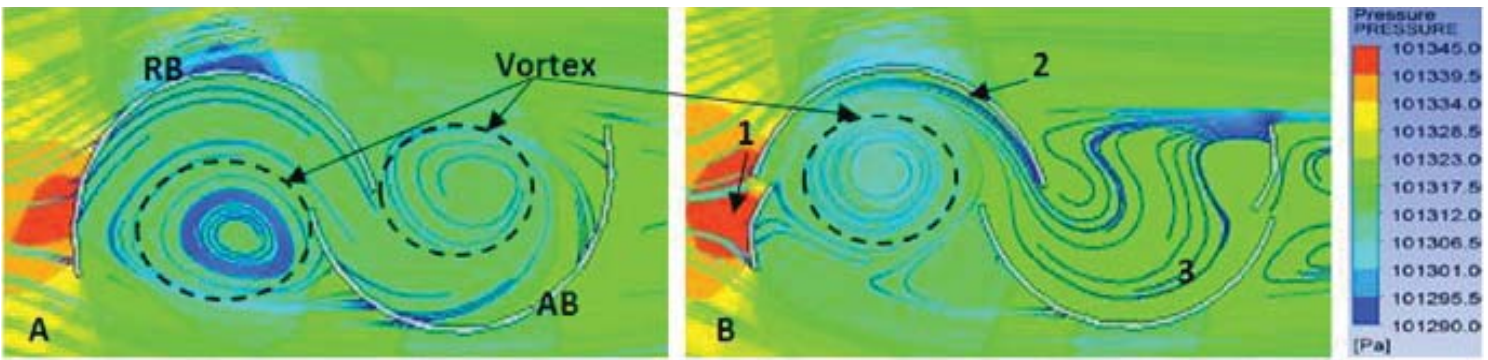

Figure 7: The pressure and streamlines profiles at the rotation angle of $165^{\circ}$

\section{(A. SC model and B. SV05 model)}


Based on the color, the value of the pressure in front of the concave area is negative because it is lower than 1 atm in both SC and SV05 models. Through the ventilation gap, the wind seemed to be sucked into the inside of the concave surface. The wind becomes concentrated in front of the ventilation gap and causes increased pressure in the ventilation gap (no. 1). Figure 7 shows if the red color on the blade (no. 1) of SV05 model looks wider than the SC model.

Figure 7 also shows if the ventilation directs the wind so that the wind follows the concave surface of the the advancing $(A B)$ and returning blades (RB). The number of streamlines in front of the concave surfaces of the returning (no. 2) and advancing blades (no. 3) of the ventilated Savonius is seen more numerous and more dense than the conventional Savonius. The phenomenon is also shown by the results of CFD simulations for the rotation angle $135^{\circ}-45^{\circ}$. It shows if the mass flow rate of air in ventilated blade is greater than the conventional Savonius at the rotation angle of $165^{\circ}$.

Increased mass flow rate of air is able to increase the pressure on the concave surface of the returning blade. Figure 7 shows if the returning blade of the SV05 model has a wider green color than the conventional Savonius model. This shows if ventilation on the blades of SV05 model are able to make the lifting force that has been working at $165^{\circ}$ rotation angle. Ventilation is able to advance the lifting force of the wind so that the wind is able to rotate the rotor before and during the $0^{\circ}$ rotation angle better. It also proves if the ventilation on the blade of the rotor models can improve a critical condition on the conventional Savonius.

\section{Vortex Comparison In Front Of The Blade Concave Surfaces}

The concave surface of the blades is the most important part of Savonius rotor for producing a positive torque. However, at a certain angle of rotation, in front of the concave surface of the blade occurs a vortex that an adverse for the rotor rotation. Figure 7 showed if the vortex is formed in front of the concave surface of the blades. Vortex will absorb some of the kinetic energy of the wind. This causes the pressure acting on the concave surface of the blade to be low.

Figure 8 show if vortex is formed at turn angle from $135^{\circ}-$ $15^{\circ}$. At the rotating angle of $135^{\circ}$, the ventilation on the SV05 blades are able to improve air flow by eliminating vortex that occurred in front of the concave side of the returning blade. At the rotating angle of $165^{\circ}$, the ventilation on the SV05 blades are able to improve air flow by eliminating vortex that occurred in front of the concave side of the advacing blade (no. 3 on fig. 4).

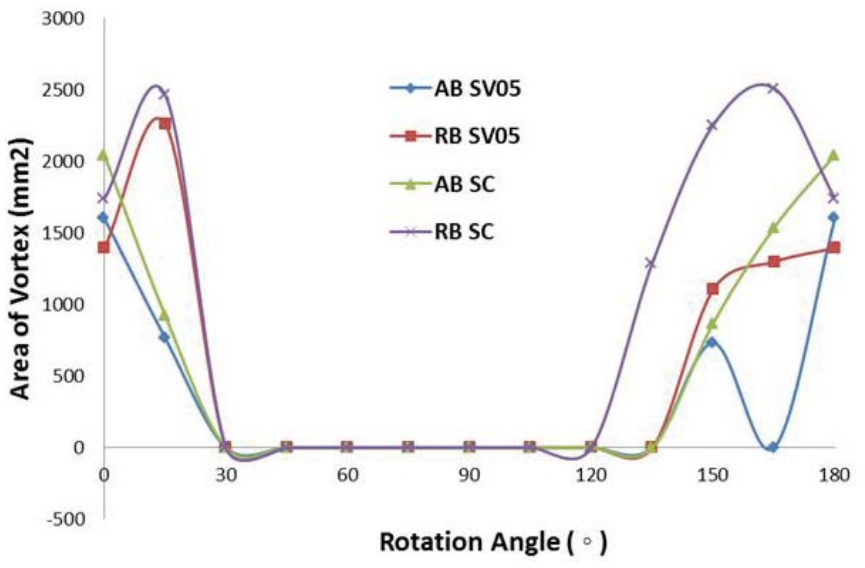

Figure 8: Vortex area in front of the concave surface on advacing and returning blades

The larger the area of the vortex then the greater the pressure difference that occurs between the center of the vortex to the outside of the circular vortex. So the loss of kinetic energy due to it is absorbed vortex also getting bigger. Ventilation on the SV05 model effectively reduces the vortex area. Thus, the kinetic energy acting on the concave surface of SV05 is larger than SC model. So SV05 is able to produce the positive torque larger than SC model.

\section{CONCLUSIONS}

The CFD simulation results show if ventilation with a $5 \%$ gap width of the blade diameter (SV05 model) has the best static torque. SV05 model can improve the static torque of Conventional Savonius by $23.8 \%$. Based on the vortex, streamline profile and distribution pressure of the simulated results, ventilation on the SV05 blade is able to increase the air mass flow rate and increase the pressure on the concave surface of the advance and returning blade by $17 \%$ and $313 \%$ larger than the SC model when the rotor rotates 180 degrees. So the vents on SV05 are able to make the rotating angle so that the SV05 rotates more easily than the SC model at both turn angles.

\section{ACKNOWLEDGEMENTS}

The authors would like to thank the Studio of Design \& Systems Engineering, Mechanical Engineering Department, Brawijaya University. Special thanks to Mr. Darto (lecturer of Mechanical Engineering Department, Merdeka University) who has taught the mastercam program. 


\section{Appendix}

\section{SC Model}

SV05 Model

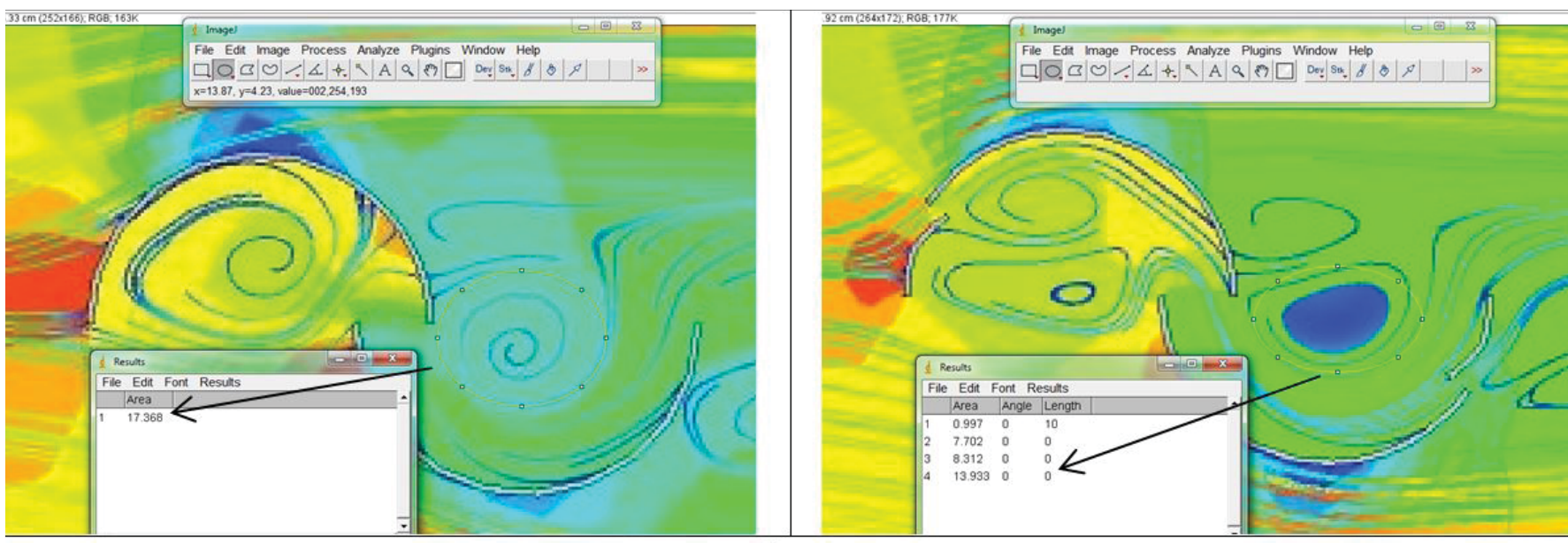

$0^{\circ}$
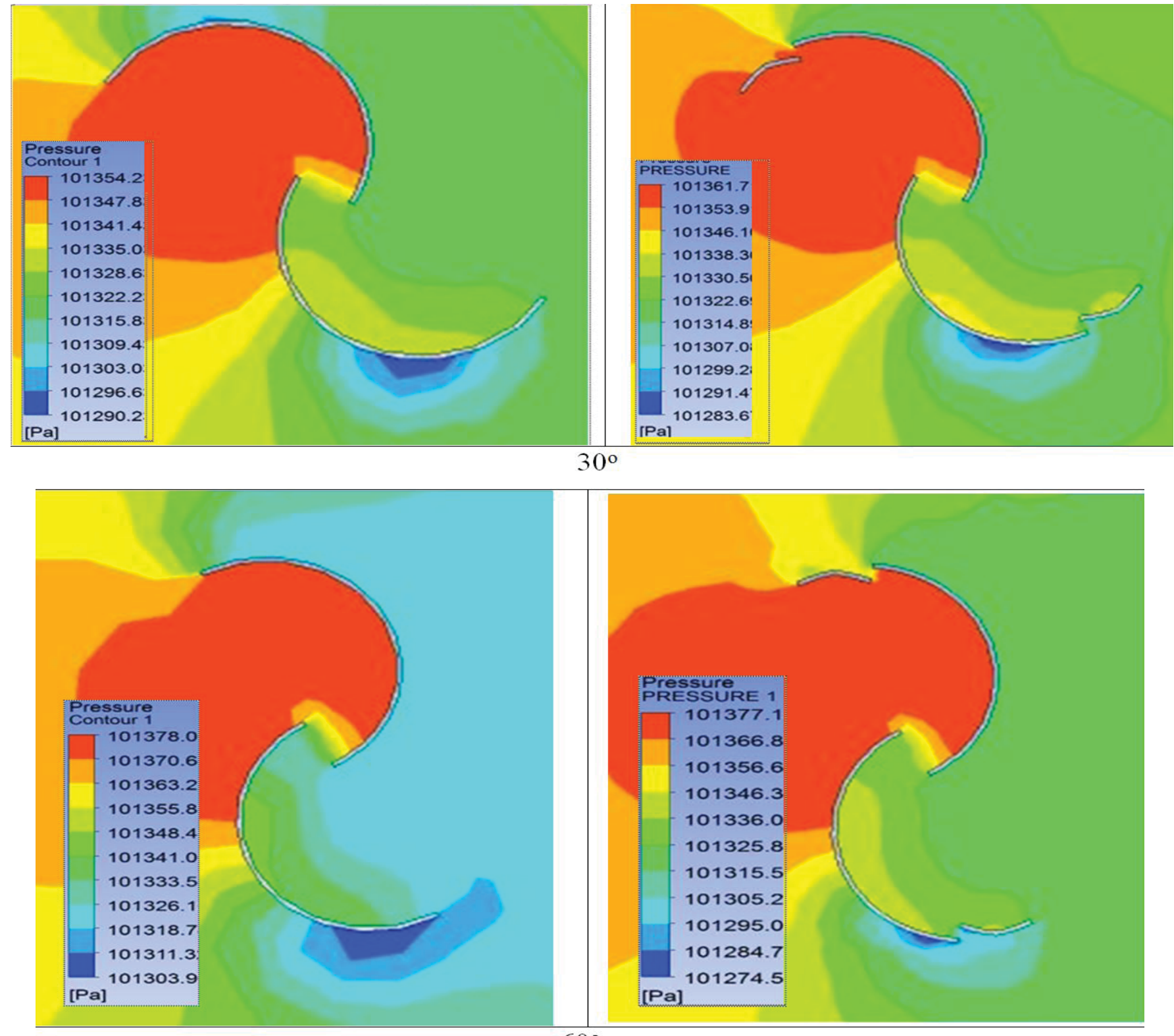


\section{SC Model}
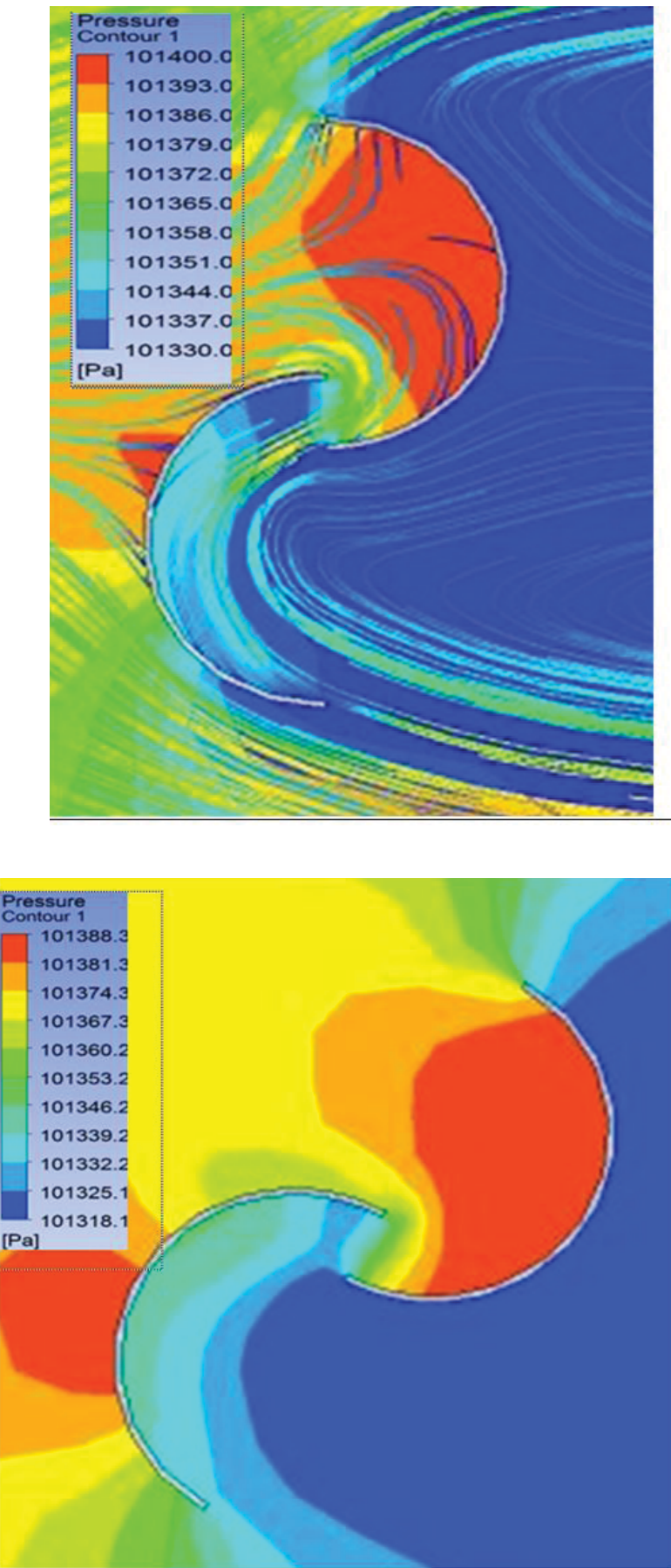

\section{SV05 Model}

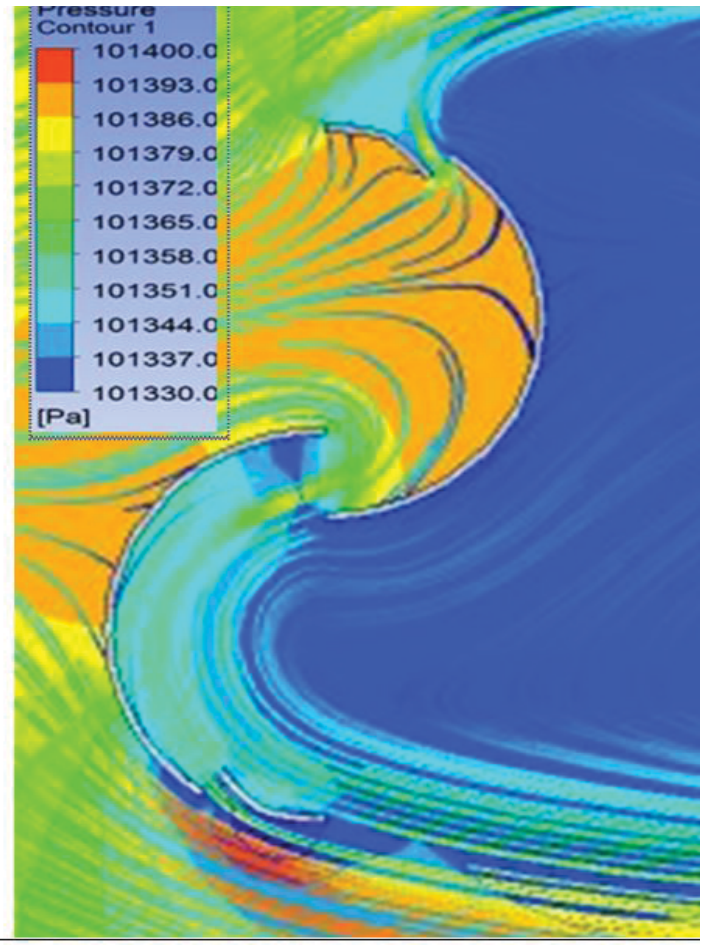

$90^{\circ}$

$120^{\circ}$
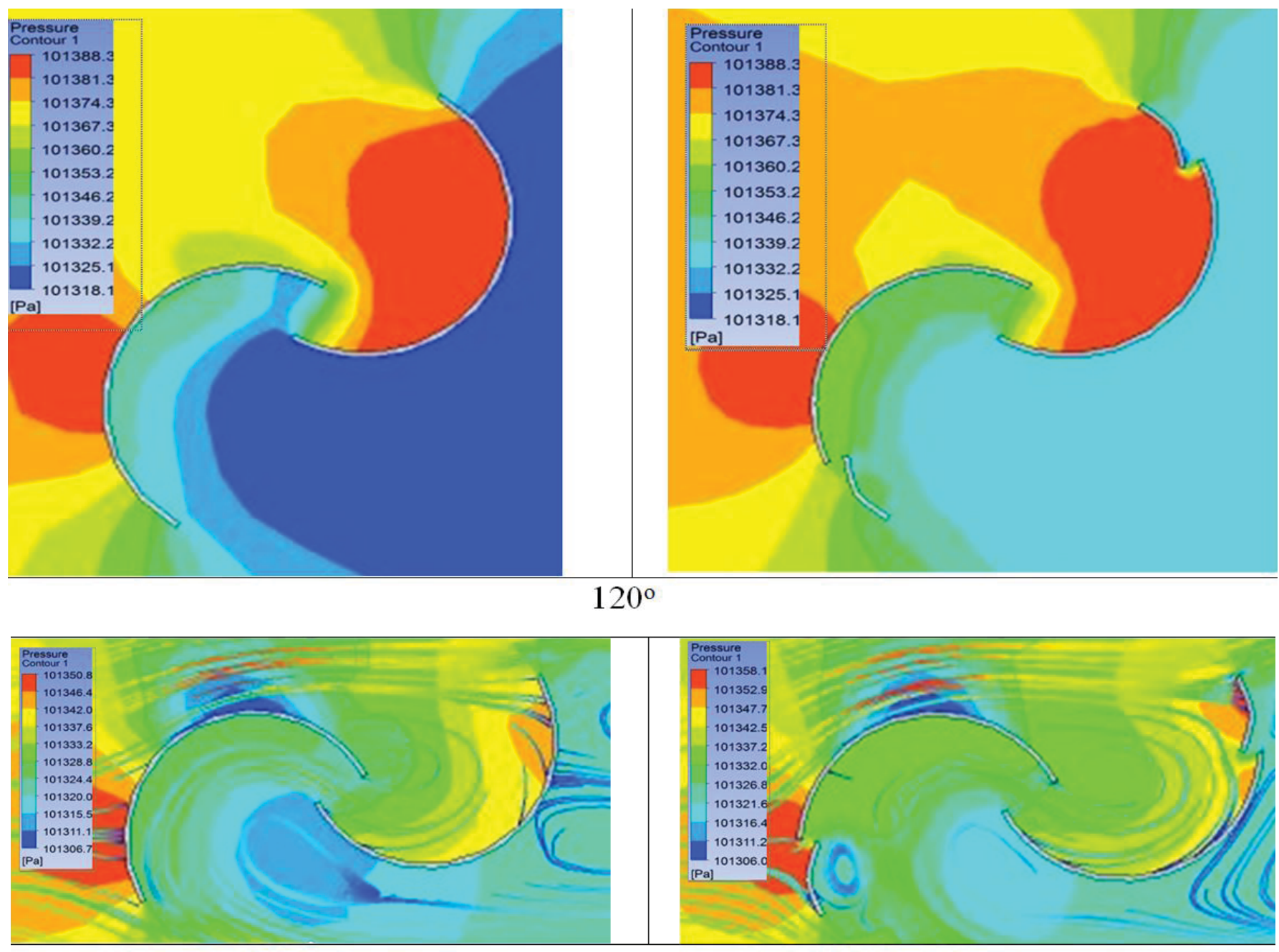


\section{REFERENCES}

1. Hariyanto, R., Soeparman, S., Denny, W., \& Mega, N.S. (2016). Experimental Study On Improvement The Performance Of Savonius Windmill With Ventilated Blade. International Journal Of Renewable Energy Research (IJRER), Vol.6, No.4, 1403-1409. (www.ijrer.org/ijrer/index.php/ijrer/article/view/4641/ pdf). Retrieved from https://www.researchgate.net/ profile/Rudy_Hariyanto2/publication/317014862 Experimental_Study_On_Improvement_The_Performance_of_Savonius_Windmill_With_Ventilated_Blade/links/591f0ccfaca272d31bd3d02c/ Experimental-Study-On-Improvement-The-Performance-Of-Savonius-Windmill-With-Ventilated-Blade.pdf

2. Tian, W., Song, B., VanZwieten, J., \& Pyakurel, P. (2015). Computational Fluid Dynamics Prediction of a Modified Savonius Wind Turbine with Novel Blade Shapes. Energies, 8(8), 7915-7929. 8(8): 79157929. doi:10.3390/en8087915

3. Ali, M.H. (2013). Experimental Comparison Study for Savonius Wind Turbine of Two and Three Blades at Low Wind Speed. Int. J. Modern Eng. Research, Vol.3 issue 5, 2978-2986. (https://pdfs. semanticscholar.org/3714/f618f873b6dace1f547dec907f9773d884f1.pdf). Retrieved from https:// www.researchgate.net/publication/286211255_Experimental_Comparison_Study_for_Savonius_ Wind_Turbine_of_Two_Three_blades_at_Low_ Wind_Speed

4. Saha, U.K., Thotla, S., \& Maity, D. (2008). Optimum design configuration of Savonius rotor through wind tunnel experiments. Journal of Wind Engineering and Industrial Aerodynamics, 96(8-9), 1359-1375. 96(89): 1359-1375. doi:10.1016/j.jweia.2008.03.005

5. Hayashi, T., Li, Y., \& Hara, Y. (2005). Wind Tunnel Tests on a Different Phase Three-Stage Savonius Rotor. JSME International Journal Series B, 48(1), 9-16. 48(1): 9-16. doi:10.1299/jsmeb.48.9

6. Kamoji, M.A., Kedare, S.B., \& Prabhu, S.V. (2009). Experimental investigations on single stage modified Savonius rotor. Applied Energy, 86(7-8), 10641073. 86(7-8): 1064-1073. doi:10.1016/j.apenergy.2008.09.019

7. Saha, U.K., \& Rajkumar, M.J. (2006). On the performance analysis of Savonius rotor with twisted blades. Renewable Energy, 31(11), 1776-1788. 31(11): 1776-1788. doi:10.1016/j.renene.2005.08.030

8. Nakajima, M., lio, S., \& Ikeda, T. (2008). Performance of Double-step Savonius Rotor for Environmentally Friendly Hydraulic Turbine. Journal of Fluid Science and Technology, 3(3), 410-419. 3(3): 410419. doi:10.1299/jfst. 3.410
9. Gupta, R., Biswas, A., \& Sharma, K.K. (2008). Comparative study of a three-bucket Savonius rotor with a combined three-bucket Savonius-three-bladed Darrieus rotor. Renewable Energy, 33(9), 1974-1981. 33(9): 1974-1981. doi:10.1016/j.renene.2007.12.008

10. Yaakob, O., Tawi, K.B., \& Suprayogi, D.T. (2010). Computer Simulation Studies on The Effect Overlap Ratio for Savonius Type Vertical Axis Marine Current Turbine. IJE Transaction A: Basic, Vol. 23, 79-88. (http://www.ije.ir/abstract/\%7BVolume:23-Transactions:A-Number:1\%7D/=1032). Retrieved from http://citeseerx.ist.psu.edu/viewdoc/download?doi $=10 \cdot 1 \cdot 1 \cdot 468.833 \&$ rep $=$ rep $1 \&$ type $=p d f$

11. Roy, S., \& Saha, U.K. (2013). Computational Study to Assess the Influence of Overlap Ratio on Static Torque Characteristics of a Vertical Axis Wind Turbine. Procedia Engineering, 51, 694-702. 51(): 694702. doi:10.1016/j.proeng.2013.01.099

12. Menet, J.L., \& Bourabaa, N. (2008). Increase in the Savonius Efficiency via a parametric investigation. ENSIAME Journal,59313. (https://www.researchgate.net/publication/228957621_Increase _ in_the_Savonius_ro.... Retrieved from https://www. researchgate.net/publication/228957621_Increase_ in_the_Savonius_rotors_efficiency_via_a_parametric_investigation

13. Zhou, T., \& Rempfer, D. (2013). Numerical study of detailed flow field and performance of Savonius wind turbines. Renewable Energy, 51, 373-381. 51(): 373381. doi:10.1016/j.renene.2012.09.046

14. D'Alessandro, V., Montelpare, S., Ricci, R., \& Secchiaroli, A. (2010). Unsteady Aerodynamics of a Savonius wind rotor: a new computational approach for the simulation of energy performance. Energy, 35(8), 3349-3363. 35(8): 3349-3363. doi:10.1016/j. energy.2010.04.021

15. Hariyanto, R., Soeparman, S., Denny, W., \& Mega, N.S. (2016). Analysis the Vortex Effect on the Performance of Savonius Windmill Based On Cfd (Computational Fluid Dynamics) Simulation and Video Recording. International Journal Of Renewable Energy Research (IJRER), Vol.6, No.3, 931-937 (www.ijrer. org/ijrer/index.php/ijrer/article/download/4063/pdf). Retrieved from http://www.ijrer.org/ijrer/index.php/ ijrer/article/view/4063/pdf

16. Pope, K., Rodrigues, V., Doyle, R., Tsopelas, A., Gravelsins, R., Naterer, G.F., \& Tsang, E. (2010). Effects of stator vanes on power coefficients of a zephyr vertical axis wind turbine. Renewable Energy, 35(5), 1043-1051. 35(5): 1043-1051. doi:10.1016/j. renene.2009.10.012

Paper submitted: 17.04.2018.

Paper accepted: 02.07.2018.

This is an open access article distributed under the CC BY-NC-ND 4.0 terms and conditions. 